\title{
DETERMINING THE SUITABILITY OF DIFFERENT DIGITAL ELEVATION MODELS AND SATELLITE IMAGES FOR FANCY MAPS. AN EXAMPLE OF CYPRUS
}

\author{
J. Drachal, A. K. Kawel \\ IGiK, Institute of Geodesy and Cartography, ul.Modzelewskiego Street 27, 02-679 Warsaw, Poland \\ (karwel, jacek)@igik.edu.pl \\ SpS4 - ICA
}

KEY WORDS: Fancy map, Image, DEM, Relief shading, hillshading, image merge, color composite

\begin{abstract}
:
The article describes the possibility of developing an overall map of the selected area on the basis of publicly available data. Such a map would take the form designed by the author with the colors that meets his expectations and a content, which he considers to be appropriate. Among the data available it was considered the use of satellite images of the terrain in real colors and, in the form of shaded relief, digital terrain models with different resolutions of the terrain mesh. Specifically the considered data were: MODIS, Landsat 8, GTOPO-30, SRTM-30, SRTM-1, SRTM-3, ASTER. For the test area the island of Cyprus was chosen because of the importance in tourism, a relatively small area and a clearly defined boundary. In the paper there are shown and discussed various options of the Cyprus terrain image obtained synthetically from variants of Modis, Landsat and digital elevation models of different resolutions.
\end{abstract}

\section{INTRODUCTION}

Fancy in English means elaborate in structure or decoration, luxurious, sophisticated or extravagant. Here using the name fancy map the authors wanted to stress that this map was made for pleasure, without an order to do it, just as a gift on the occasion of the trip of fellow Professor to Cyprus. Perhaps the use of the word fancy in this context is unfortunate, which results from our poorly English, but there is no retreat now as it has already gone in the abstract of the article.

In order not to prolong the mystery, the article is about the execution of image maps from the source materials available in the internet, which is illustrated by the example of a map of Cyprus. Theoretically, also the free software from the internet should be used to make the job, but at this stage our experience is not sufficient to say if the software used currently by us could be replaced.

We assumed that for Professor, beside the map of Cyprus bought in a kiosk at the airport, such a map could prove to be useful for a variety of terrain analysis or to detect curiosities worth checking, perhaps to mark places and notes on them, and generally for a deeper view and understanding of the Cypriot space. Certainly we did not intend to spend too much time on it.

\section{COMPILATION OF THE MAP}

\subsection{Characteristic of image data}

We planned to download material available and think about what this can do. We had ESRI ArcMap software, ADOBE Photoshop and SURFER of Golden Software. We wanted an image in natural colors as detailed as possible and inspiring, i.e. stimulating the imagination. We gathered satellite imageries and digital terrain models needed to make hillshading images and also vector data available for Cyprus at reliable geofabrik portal. The following satellite imageries were used:

MODIS - an average scene from August 2004, true colors, ground resolution $500 \mathrm{~m}$; THEMATIC MAPPER - 2 scenes from Nov.27, 2015, one scene from Dec.04, 2015, visible channels 2, 3, 4 (blue, green, red), ground resolution $30 \mathrm{~m}$, panchromatic image (channel 8), ground resolution $15 \mathrm{~m}$; color composite in natural colors made by NASA, ground resolution $30 \mathrm{~m}$.

The area of the island was covered with three TM scenes that required mosaicing, and each was recorded with 16 bits per channel. Conversion to 8-bit channels took place without losses because the entire record, as could be observed on the histogram, was originally focused on the first 8 bits. Mosaicing was also facilitated because the scenes had the same geometry, and it was enough to slide one on the other without any error (Helmert transformation) in Photoshop. The scenes were not georeferenced (not geotiff). The other two kinds of data, i.e. hillshading images and vector data had the georeference and could be placed to ArcMap to construct the database for Cyprus.

\subsection{Data image preparation}

After mosaicing each of 2, 3, 4 channels we made a composite image in true colors named COMPO and we compared it with mosaiced color composite of NASA (we named it NASA). Having panchromatic image of Cyprus we used it to improve the ground resolution of each composite creating COMPO_P and NASA_P. To do this it is enough to enter both channels into the arithmetic relationship with each other and the result will contain the information of both of them (Drachal, 1994).

The simplest method is to replace the existing Intensity component of the image by the panchromatic channel of higher resolution, when the RGB image is presented in IHS color space or, as in Photoshop, Lab color space. This procedure was applied to obtain COMPO_P image. In case of NASA however, probably due to the use of the InfraRed channel in the composite, simple replacement of the Intensity component produced an image with heavily spoiled good color scheme. Therefore in this case a relation of channel multiplication was used. The operation is referred to as pan sharpening. A fragment of the best image (NASA_P \} in full detail is presented in Figure 1. One may notice delicate, barely visible line-work showing roads, settlements and river valleys. 


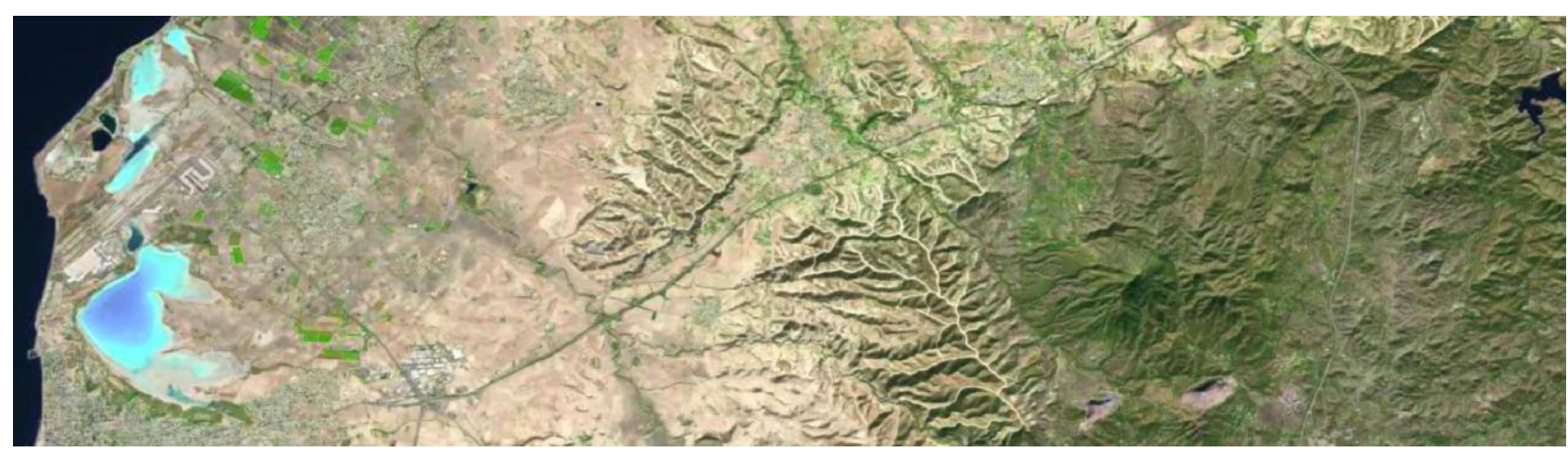

Figure 1. Fragment of one of the colected images in full resolution, oriented to the south to enhance natural hillshading (NASA_P)

\subsection{Characteristic of Digital Terrain Model}

The following digital terrain models were reviewed: GTOPO30, SRTM-30, SRTM-3, SRTM-1 and ASTER. GTOPO-30 is equivalent to SRTM-30 therefore has been omitted as inferior [Drachal et al, 2013]. The others were used to produce hillshading images (shaded relief) for the sun height of $30^{\circ}$ and the direction NW (Fig. 2). overall perception. The only way out is to rotate the map upside down which is quite reasonable and justified until encountering difficulties. You might be mistaken about $180^{\circ}$ in directions and lose time. Also such a map can't be compared with other maps. For this reason, you can place an elevation model under the image, but then a large part of the picture is lost and what is left is just a composition of colors (Patterson, 2004). However, it is a solution and we did it.

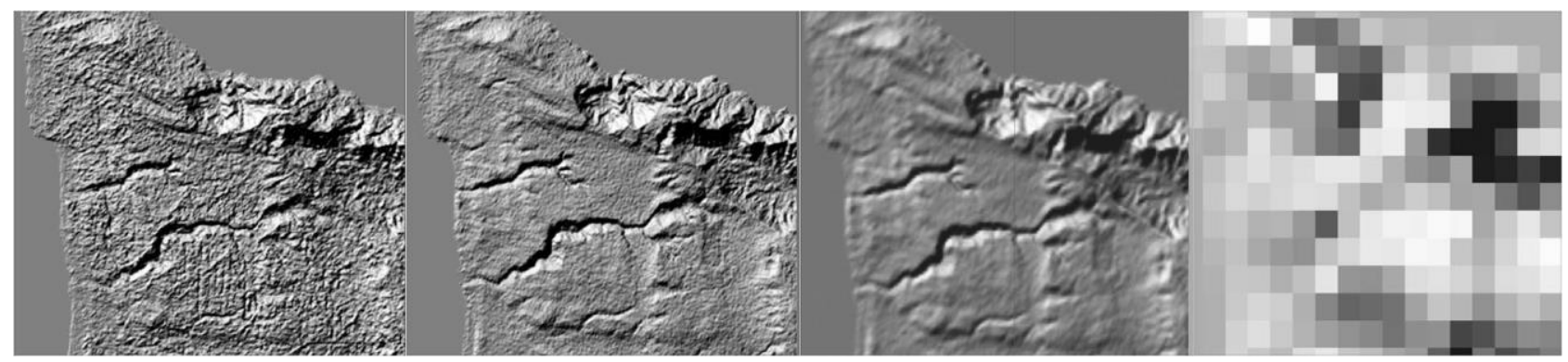

Figure 2. Fragments of collected DEMs in the form of hillshading images presented here in the 2x reduced resolution of SRTM-1 (approx. 60 m). From the left: ASTER, SRTM-1, SRTM-3, SRTM-30

SRTM-30 has a gridding structure with 30" postings (approximately $1 \mathrm{~km}$ ), SRTM-3 about $100 \mathrm{~m}$, SRTM-1 approximately $30 \mathrm{~m}$ and ASTER also $30 \mathrm{~m}$ ASTER model was abandoned because of the large jumps (noise) on flat areas. In Fig. 2 there are four DEMs presented at a scale of about 1:200 000 (visible noise in ASTER image first from the left) (Rodrigues et al., 2006, Karwel et al., 2008, Jacobsen, 2008, Crippen, 2010).

\subsection{Data Terrain Model preparation}

The collected material was reviewed to decide about further action. It was decided to investigate the combination of two DEMs and three images, together 6 items. The SRTM-30 and SRTM-1 were selected DEMs whereas ASTER was left earlier and SRTM-3 was decided to leave now because of expected results very similar to SRTM- 1 . The selected images were NASA_P, COMPO_P and MODIS whereas expected results from NASA and COMPO would closely repeat the results of their pan-sharpened versions.

\section{RESEARCH}

The aim was to create a combination of the image and DEM useful for making the map. Although in the image there are shadows created naturally by the sun, they do not produce 3-dimmensional effect of convexity in the right place, instead valleys look like mountain ridges. This is false and even reduces
Six combinations of selected satellite images and hillshading images produced from selected DEMs were to be investigated with the use of procedures developed in Photoshop software. Generally, these procedures consists of placing RGB images and hillshading images having the same geometry as consecutive layers of some expected resulting image which would contain information of each component. Each image can be placed repeatedly and to blend the information it is necessary either to reduce opacity from $100 \%$ down, or to use some arithmetic relation between layers (Drachal et al., 2013). We used relations named multiply, overly and screen.

\subsection{Variant COMPO_P / SRTM-1}

To connect the image COMPO_P with the model SRTM-1 the following procedure was used: a hillshading image SRTM-1 having $50 \%$ opacity was placed on a white background. It was covered with COMPO_P image with the opacity of $100 \%$ but with overly function and again the image COMPO_P this time the with opacity of $50 \%$ and multiply function. Then, from another copy of the COMPO_P image the image of edges was made using the function find edges. This image was then treated as a new channel for the selection of line-works from the original COMPO_P image. So removed line-works was put twice on the top of current set of layers. The resulting image already contained an inverted shading of slopes but had not the proper color. It has been multiplied by its copy of increased 
The International Archives of the Photogrammetry, Remote Sensing and Spatial Information Sciences, Volume XLI-B4, 2016 XXIII ISPRS Congress, 12-19 July 2016, Prague, Czech Republic

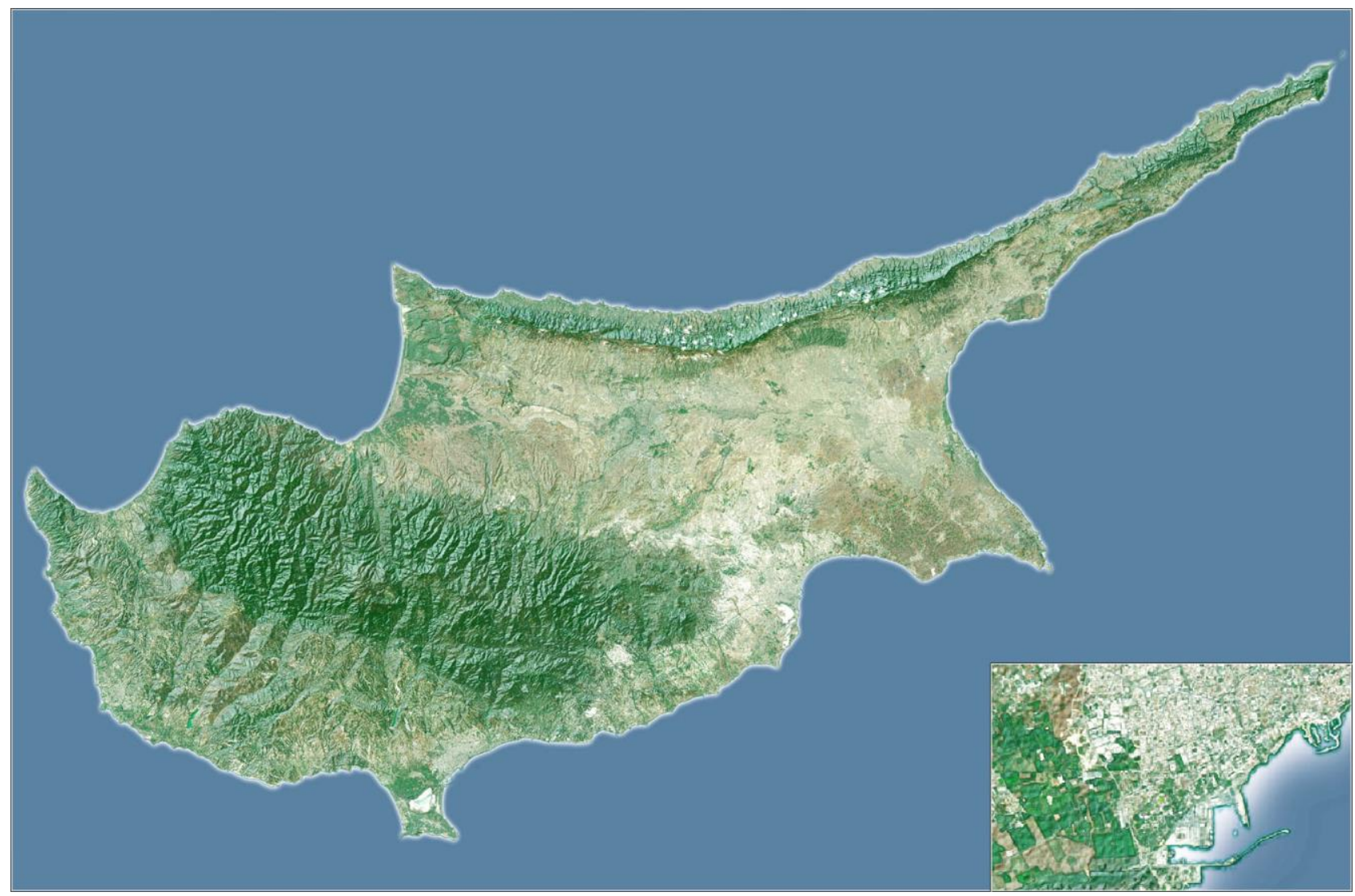

Figure 3. Composition of the COMPO_P image with SRTM-1. Note: fragment in full resolution in the inset

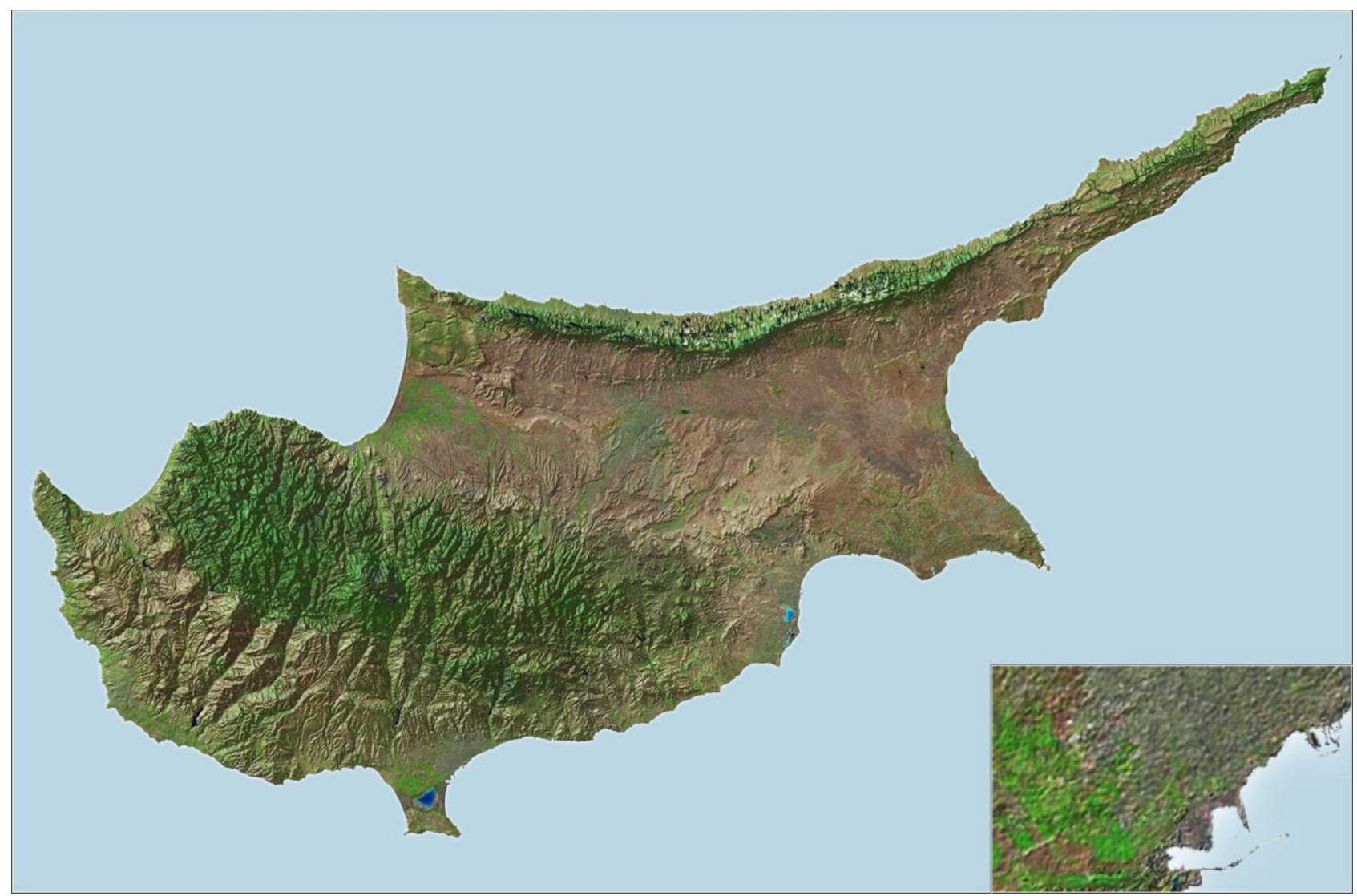

Figure 4. Composition of the NASA_P image with SRTM-1. Note: fragment in full resolution in the inset 
by $40 \%$ saturation of colors (function multiply) and overlied by a subsequent copy of increased to $40 \%$ saturation (function overly). The effect was used to further works and is presented in Fig. 3.

\subsection{Variant NASA_P / SRTM-1}

To merge NASA_P image with the model SRTM-1 the following procedure was applied: a hillshading image of SRTM-1 with $75 \%$ opacity was placed over the RGB image NASA_P. Then three special copies of the image NASA_P were made in following way: channel red of the RGB image was used as a basis for the selection (after inversion) of the first copy of the original, green channel for the selection of a second copy, and blue for the selection of a third.

The resulting copies retain the original line-work but are to some degree transparent. When superimposed as three successive layers they reproduce the original. In this case, they have been used in the form of 3 successive layers to cover hillshading image: the first and second as overlay and a third as screen. To enhance contrast the resulting image was overlayed by its copy. The final result is shown in Fig. 4.

\subsection{Variant NASA_P / SRTM-30}

The above procedure was used to hillshading image of SRTM30. As a result only the biggest shadows has been reversed and generally an image looks unnatural because the old shadows were confused with the new (RYS_5). Having this result the connection of SRTM-30 with COMPO_P has not been studied.

For comparison, to see how the new shadows replace the old, the same passages as on Fig.5 were selected for variant 1 and 2 . The results are in Figure 6 and 7. In variant 1 new shadows are not so visible, but you can see more line-works (roads). For option 2 line-works is essentially invisible, and the new shadows are clear.

\subsection{Variant MODIS / SRTM-30 or SRTM-1}

The combination of MODIS image with SRTM-30 looks naturally but blurry (Fig 8). It would present well in a much smaller scale (Fig. 10). On the other hand the combination of MODIS with SRTM-1 gave a good picture to be presented even at a medium scale (Fig 9) showing the simplified colors of land cover, particularly vegetation, against the background of a clear hillshading image, showing all irregularities in the field. The image is very similar to that of Fig. 7, where only colors remained from the NASA_P image.

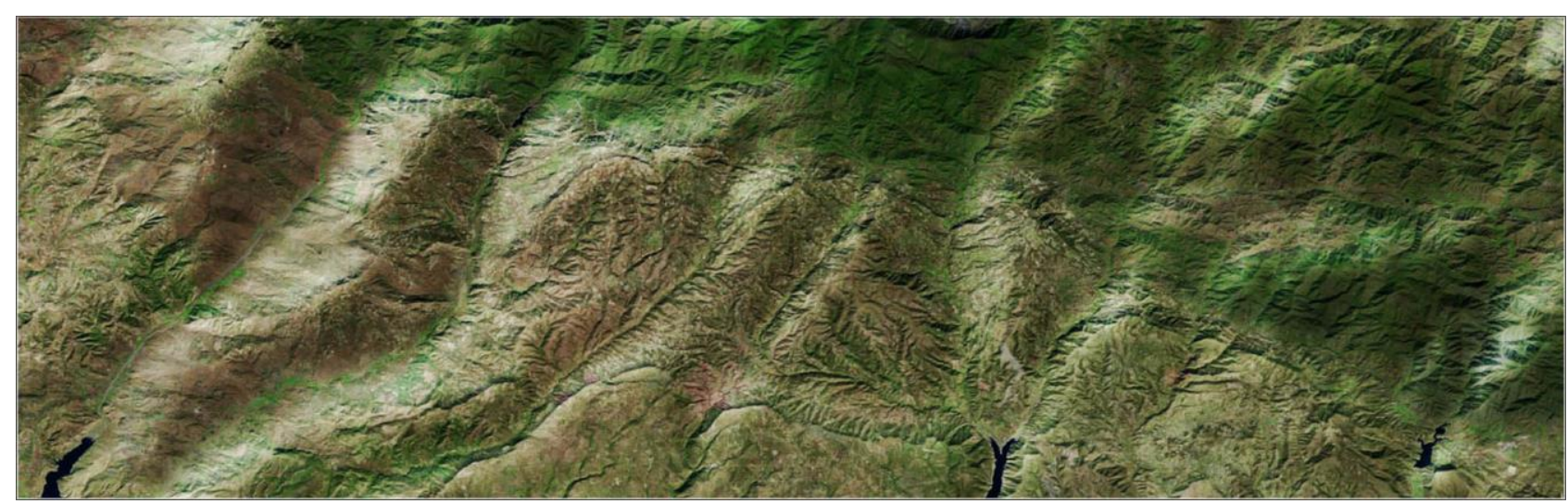

Figure 5. Connection of NASA_P image with SRTM-30. Full resolution reduced twice to show greater area (scale 1:400 000 approx)

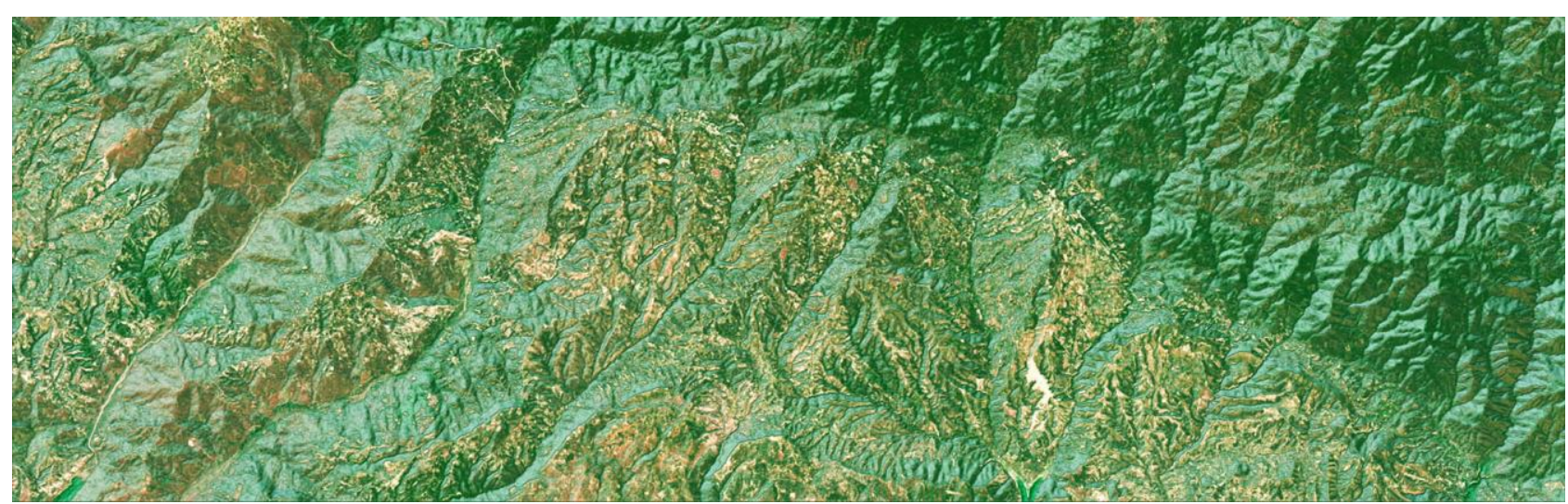

Figure 6. Connection of COMPO_P image with SRTM-1. Full resolution reduced twice to show greater area (scale 1:400 000 approx) 


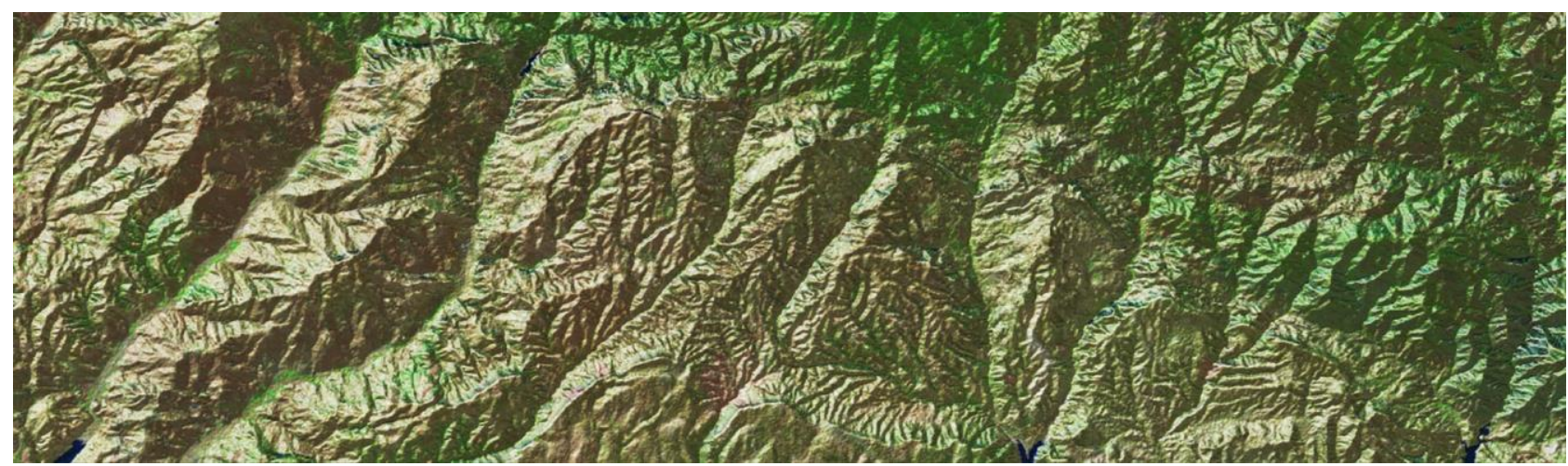

Figure 7. Connection of NASA_P image with SRTM-1. Full resolution reduced 2x to show greater

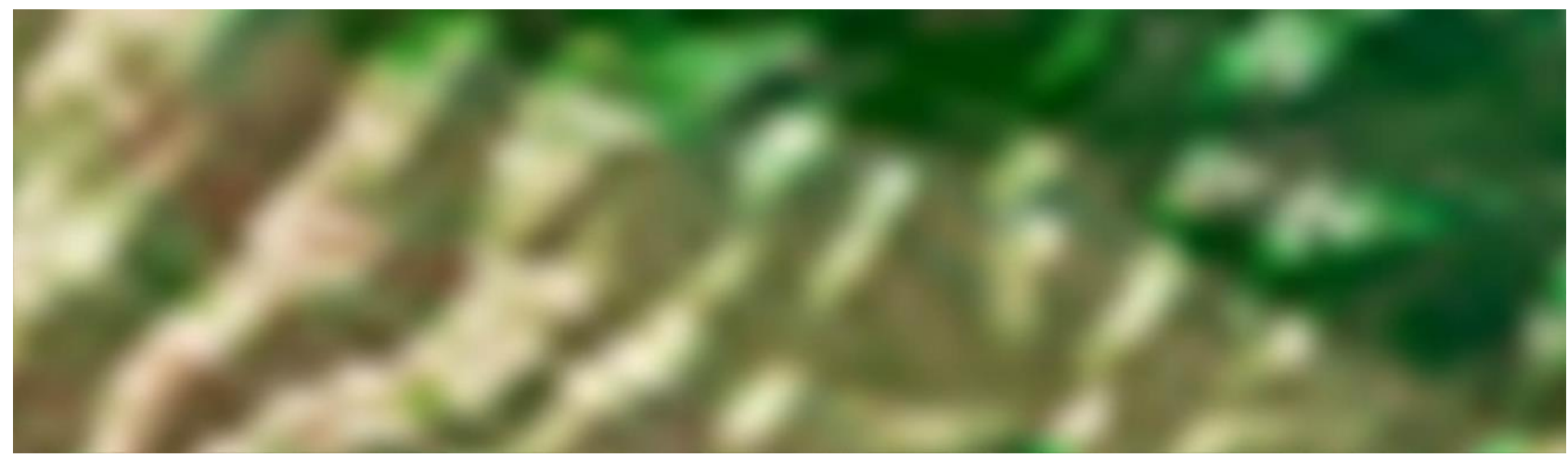

Figure 8. The combination of MODIS image with SRTM-30. Full resolution reduced $2 \mathrm{x}$ to show greater area (scale 1:400 000 approx)

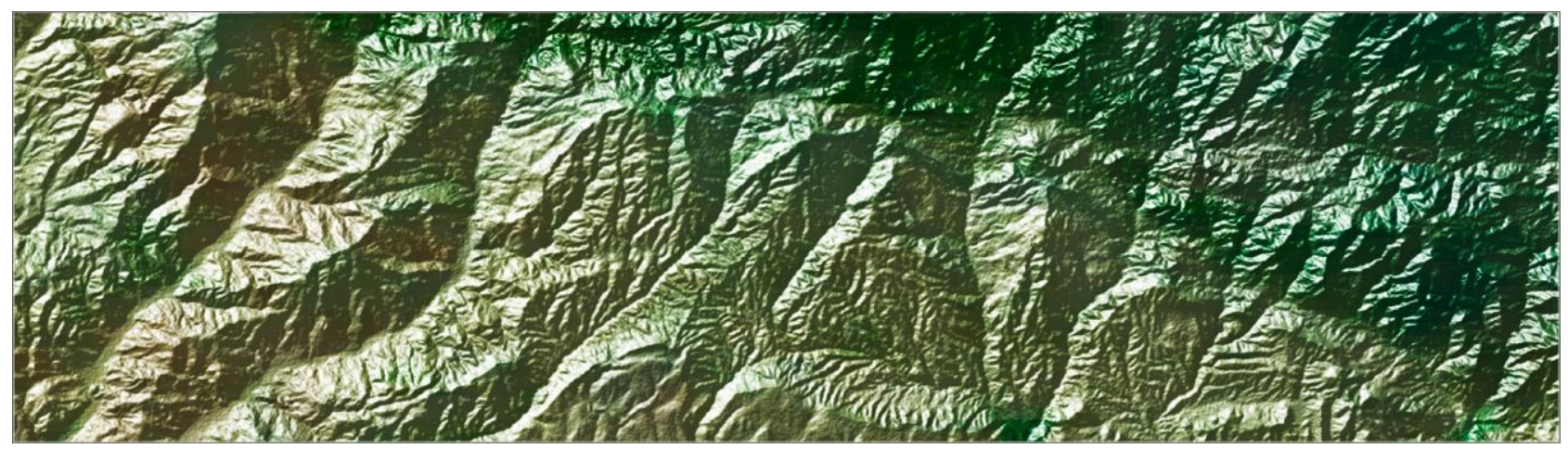

Figure 9. The combination of MODIS image with SRTM-1. Full resolution reduced 2x to show greater area (scale 1:400 000 approx)

\subsection{Ground resolution}

From the research it can be seen that the best results provide combinations of RGB image and DEM of similar resolution in the range $2 x$ or $3 x$ to one another, as e.g. SRTM-1 and NASA_P where it was 30:15. In the case of SRTM-30 and MODIS it is 1000: 500, in the case of SRTM-3 and MODIS which actually was not investigated, it is 100: 500. You could say that the ground resolution has a decisive influence on the scale of developed maps because the digital picture element (pixel) should be marked as a point the same on paper as on the screen, which can be converted assuming 300dpi $(0.1 \mathrm{~mm})$ for a paper on the equation: scale denominator $=$ ground resolution in millimeters x 10 , for example, for ground resolution of $30 \mathrm{~m}$ it is 300000 .

The map on the screen may be presented at a scale $2 \mathrm{x}$ bigger, which is in this example, 1: 150000 , because the screen point size is approximately $0,2 \mathrm{~mm}$, and the image looks sharp.
An image MODIS connected to SRTM-30 at scale 1:10 million looks very pictorial and could be used in other situations (Fig. 10).

\subsection{Making the map}

In the image there are marked things, which by reason of the scale you can't see or be seen indistinctly, namely, cities, rivers and roads, and besides the city names. There have been made only the simplest selection of objects using the attribute table, for example, town, city or primary road, motorway. Devoting more time, you can select the content of the vector in more detail according to your places of residence and interests. Finally, the map looked like this - Fig. 11 in all, and Fig. 12 at a scale of about 1: 200000 . 


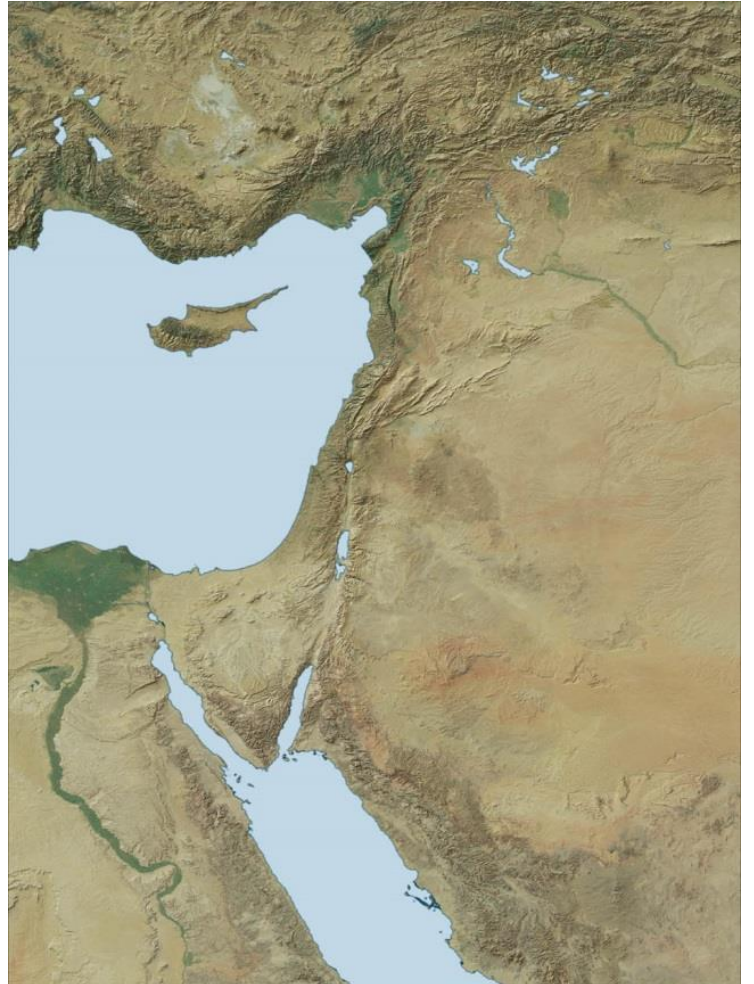

Figure 10. MODIS image merged with SRTM-30 DEM. Here at scale approx. 1: 10000000

\section{CONCLUSION}

We live in times when such things as developing the real, useful map are possible, but not too many people want to do it, leaving this to amateur cartographers.
It is actually possible to develop your own database on a specific location and to produce maps in your own way for your own needs, and they may be compatible to other maps.

It turns out that there are relevant free softwares such as SAGA GIS and QGIS. Obviously this is a message for those who like maps and have ideas, because the justification for the existence of such maps is limited. Admittedly, such a map could be a help or a decoration on your website, it could be a decoration of the office, but also a set of such maps could create an atlas for schools with a different potency from these existing.

The information from remote sensing imaging and elevation mapping is unprecedented and uncommon despite we get already used to it. It remains exceptional and give us an unusual view on our planet Earth. The combination of this informations allows for producing general maps where the Earth's surface has completely new look when compared to older maps, and this new look resembles reality. Such new maps neatly developed by cartographers could have positive influence on students by creating more realistic image of the world in their minds (Montello, 2002).

Evidently the quality of the data is essential and so is matching the data to the scale of a planned map. In our case we could see that the delicate line-work of Landsat image could not be transferred to the hillshading image which actually gave an effect similar to that of MODIS, despite huge difference in ground resolution of these two types of data. The conclusion is that there is a range of image scales (or ground resolutions) that there is no real difference in depicting the Earth's surface, roads and houses are clearly visible only on 1-2 m ground resolution images or 1:10 $000-1: 20000$ scales. This is specificity of images and also the advantage of traditional maps drawn by hand.

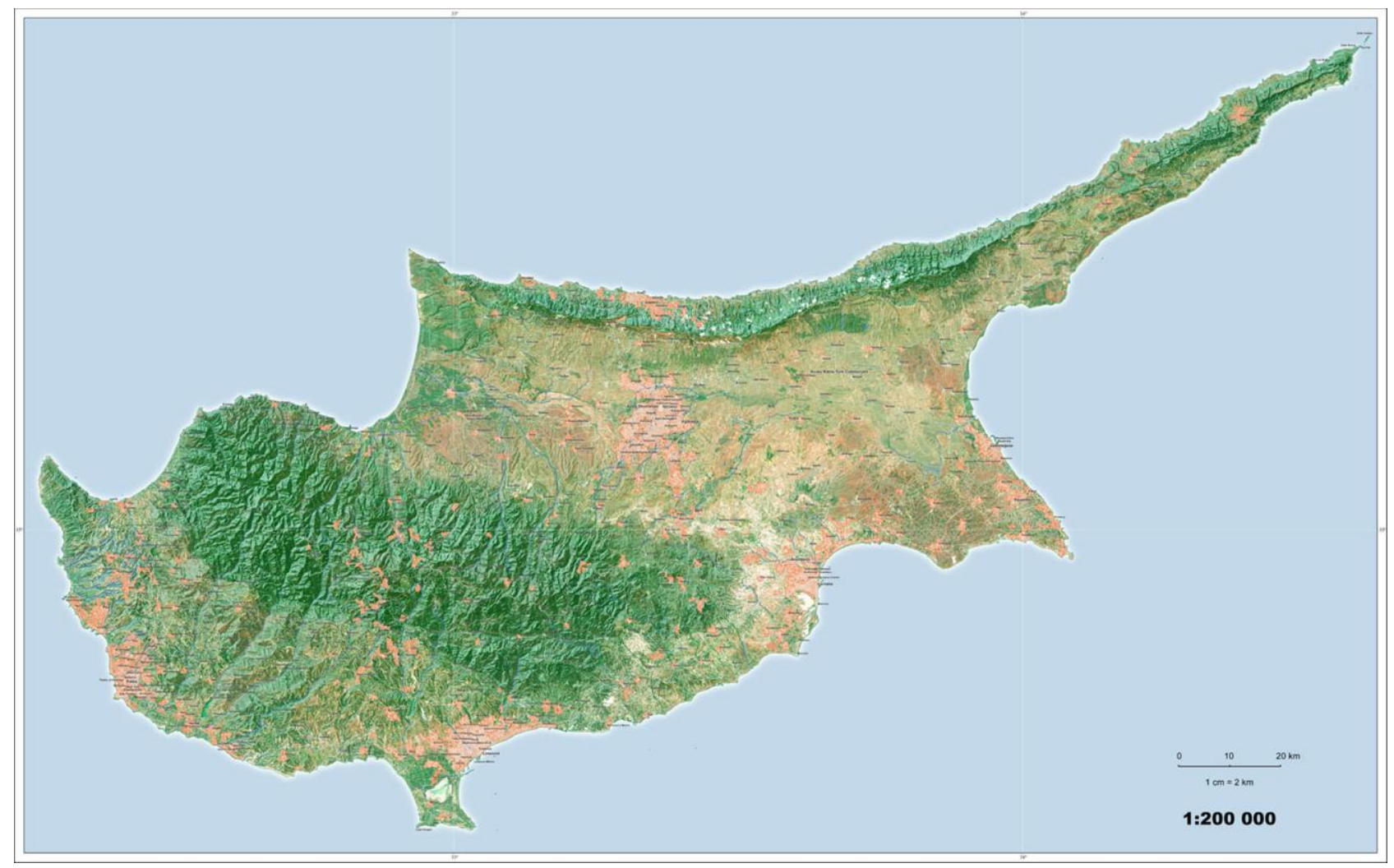

Figure 11. Map of Cyprus at scale 1:200 000 reduced here to scale approx. 1:1.6 Million 


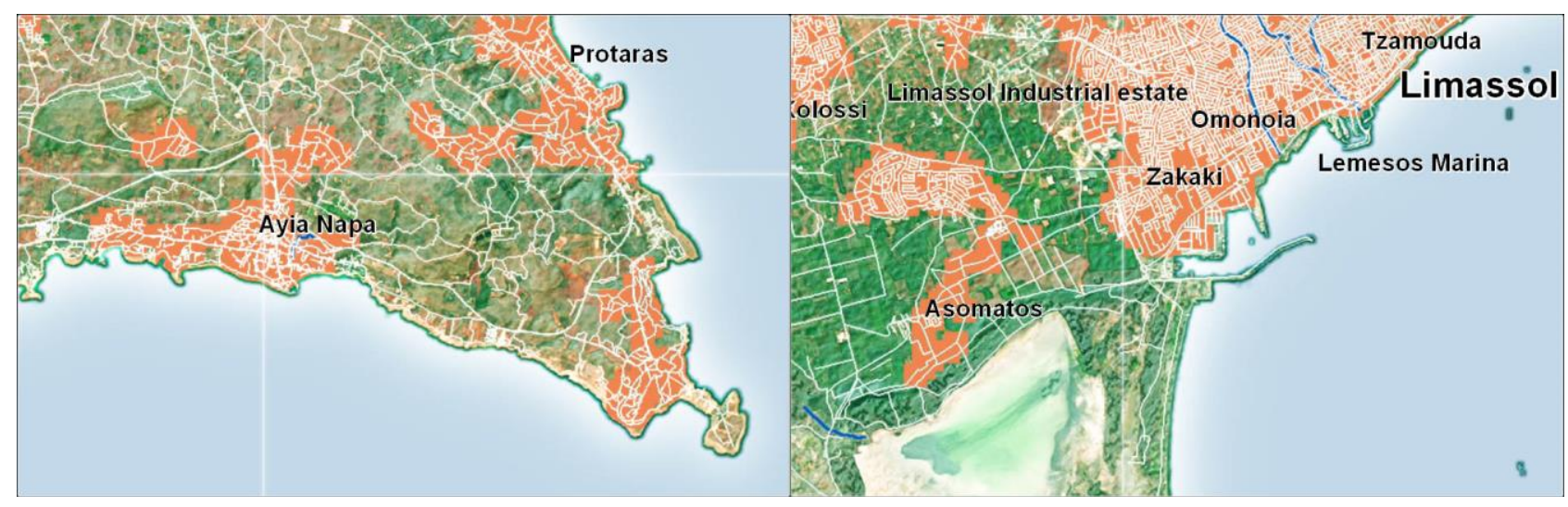

Figure 11. Map of Cyprus: details at scale 1:200 000

\section{REFERENCES}

Crippen R. E., 2010. Global topographical exploration and analysis with the SRTM and ASTER elevation models, Geological Society, London, Special Publications 2010; v. 345; p. 5-15.

Drachal J., Dębowska A., 2013. Towards a More Realistic Depiction of the Earth's Surface on Maps. Pure and Applied Geophysics, May 2013, Springerlink.com DOI 10.1007/s00024013-0684-8 pp 1061-1075.

Drachal, J.,1994. Zwiększenie rozdzielczości obrazu barwnego w wyniku syntezy z panchromatycznym obrazem czarno-białym o wyższej rozdzielczości. Warszawa. Prace Instytutu Geodezji i Kartografii, Tom XLI, zeszyt 89, pp. 131-140.

Jacobsen K., 2006. SRTM HEIGHT MODELS. GEOconnexion International Magazine, August, s.20-21.

Karwel A.K., Ewiak I., 2008. Estimation of the accuracy of the SRTM terrain model on the area of Poland. The International Archives of the Photogrammetry and Remote Sensing. XXI ISPRS Congress, XXXVII, B7, Comm. VII, pp. 169 - 172. Beijing.

Montello D., (2002). Cognitive map-design research in the twentieth century: Theoretical and empirical approaches, Cartography and Geographic Information Science, Vol. 29, No. 3, pp. 283- 304 .

Patterson T, Kelso N, 2004. Hal Shelton Revisited: Designing and Producing Natural-Color Maps with Satellite Land Cover Data.

Rodrigues E., Morris C. S., Belz J. E., 2006. A Global Assessment of the SRTM Performance. Photogrammetric Engineering \& Remote Sensing, s.261 - 267. Remote Sensing, XX ISPRS Congress, XXXV, B1, Comm. I, pp. 474 - 478.

http://www2.jpl.nasa.gov

http://www.shadedrelief.com/shelton/a.html 